\title{
(2) OPEN ACCESS \\ Investigation of meropenem stability after reconstitution: the influence of buffering and challenges to meet the NHS Yellow Cover Document compliance for continuous infusions in an outpatient setting
}

\author{
Conor Jamieson, ${ }^{1}$ Michael Charles Allwood, ${ }^{2}$ Donata Stonkute, ${ }^{2}$ Andrew Wallace, ${ }^{2}$ \\ Alan-Shaun Wilkinson, ${ }^{2}$ Tim Hills, ${ }^{3}$ on behalf of the BSAC Drug Stability Working Party
}

${ }^{1}$ Pharmacy Department, Sandwell and West Birmingham Hospitals NHS Trust, Birmingham, UK ${ }^{2}$ Biopharma Stability Testing Laboratory Ltd, Nottingham,

${ }^{3}$ Pharmacy Department and OPAT Service, Nottingham University Hospitals NHS Trust, Nottingham, UK

Correspondence to Dr Conor Jamieson, Pharmacy Department, Sandwell and West Birmingham NHS Trust, Birmingham, B18 7QH, UK; conor.jamieson@nhs.net

Received 27 July 2018 Revised 19 November 2018 Accepted 28 November 2018 Published Online First

13 January 2019

EAHP Statement 5: Patient Safety and Quality Assurance.

\begin{abstract}
Objectives To determine the influence of different buffers, $\mathrm{pH}$ and meropenem concentrations on the degradation rates of meropenem in aqueous solution during storage at $32^{\circ} \mathrm{C}$, with the aim of developing a formulation suitable for 24-hour infusion in an ambulatory elastomeric device, compliant with the latest National Health Service Pharmaceutical Quality Assurance Committee Yellow Cover Document (YCD) requirements.
\end{abstract}

Methods Meropenem was diluted to $6.25 \mathrm{mg} / \mathrm{mL}$ and $25 \mathrm{mg} / \mathrm{mL}$ in aqueous solutions adjusted to various $\mathrm{pH}$ with phosphate or citrate buffer and assessed for stability. Meropenem concentrations were determined using a validated stability-indicating high-performance liquid chromatography method at time 0 and following storage for up to 24 hours at $32^{\circ} \mathrm{C}$ as per the YCD requirements.

Results Degradation was observed to be slowest in citrate buffer around $\mathrm{pH} 7$ and at a meropenem concentration of $6.25 \mathrm{mg} / \mathrm{mL}$; however, losses exceeded $10 \%$ after storage for 24 hours at $32^{\circ} \mathrm{C}$ in all of the diluents tested in the study.

Conclusions Meropenem at concentrations between $6.25 \mathrm{mg} / \mathrm{mL}$ and $25 \mathrm{mg} / \mathrm{mL}$ as tested is not sufficiently stable to administer as a 24-hour infusion in ambulatory device reservoirs. If the YCD 95\% minimum content limit is applied, the infusion period must be reduced to less than 6 hours for body-worn devices, especially at the higher concentration studied $(25 \mathrm{mg} / \mathrm{mL})$. This limits the possibility of using elastomeric devices to deliver continuous infusions of meropenem as part of a wider outpatient parenteral antimicrobial therapy service.

\section{INTRODUCTION}

Meropenem is a broad-spectrum carbapenem antibiotic with clinical utility in a wide range of multidrug-resistant Gram-negative infections. ${ }^{1}$ Outpatient parenteral antimicrobial therapy (OPAT) is becoming an increasingly important model for managing infections both in the UK and worldwide. It has a number of benefits which include increased patient convenience and increased capacity within healthcare systems with commensurate clinical outcomes to an inpatient stay in hospital. ${ }^{2}$ Currently, the usefulness of meropenem within OPAT is limited by the practicalities of a multiple-daily dosing regimen. ${ }^{3}$ Many OPAT services favour once-daily dosing of antimicrobials for patient convenience and service delivery considerations. There are a number of elastomeric pump devices available for ambulatory delivery of antimicrobials that deliver a continuous infusion (CI) of drug over a 24-hour period, and we have recently reported on the stability of flucloxacillin in these devices. ${ }^{4}$ Several studies have reported favourable outcomes from using a CI of meropenem compared with intermittent infusion. ${ }^{56}$

Meropenem is known to be relatively unstable after reconstitution and dilution in $0.9 \%$ saline or $5 \%$ glucose. Degradation rates are relatively high and present challenges when assigning a practical shelf-life to injections in ready-to-administer containers. $^{7} 8$ Infusion periods not exceeding 12 hours have been reported. This is especially true for ambulatory devices which require supporting evidence for solutions stored at $32^{\circ} \mathrm{C}$ throughout the administration period to be compliant with the UK National Health Service (NHS) Yellow Cover Document (YCD) requirements. ${ }^{9}$ All previous studies have been conducted using 0.9\% saline as diluent. Meropenem stability has been shown to be influenced by temperature, ${ }^{7} \mathrm{pH}^{10} 11$ and drug concentration. $^{712}$ The apparent optimum $\mathrm{pH}$ for stability is approximately $\mathrm{pH} 6 .^{7}$ Degradation rates also increase at higher concentrations, which is of particular relevance when treating multidrugresistant infections.

The aims of this study were to determine the influence of different buffers, $\mathrm{pH}$ and meropenem concentrations on the degradation rates of meropenem in aqueous solution during storage at $32^{\circ} \mathrm{C}$, with the aim of developing a formulation suitable for 24-hour infusion in an ambulatory elastomeric device, compliant with the latest NHS Pharmaceutical Quality Assurance Committee YCD requirements. ${ }^{9}$

\section{MATERIALS AND METHODS}

\section{Materials}

The chemicals used were high-performance liquid chromatography (HPLC)-grade acetonitrile, CAS 75-05-08 (Fisher Scientific, Loughborough, UK), orthophosphoric acid (Fisher Scientific), sodium 
phosphate dibasic (Acros Organics, Geel, Belgium), tri-sodium citrate dihydrate, CAS 6132-04-03 (Sigma Aldrich, Dorset, UK), and citric acid, CAS 5949-29-1 (Fisher Scientific), all of analytical grade. Milli-Q $>18$ mega-Ohm purified water was generated in the laboratory (Elix Merck Millipore, Watford, UK). Meropenem powder for injection (Demo SA, Noriderm Enterprises, Nicosia, Cyprus) was supplied by the Royal Derby Hospital pharmacy stores. Citrate $(0.3 \% \mathrm{w} / \mathrm{v})$ buffered sodium chloride pH 7, $100 \mathrm{~mL}$, was supplied by Preston Pharmaceuticals (Royal Preston Hospital, Preston, UK).

\section{Chromatographic apparatus and conditions}

A stability-indicating liquid chromatography method employing a Thermo Scientific Ultimate (U3000) HPLC System with diode array ultraviolet detection and Chromeleon V.6.8 software operating under Windows 7 was adapted from a published method. ${ }^{11}$ The HPLC column was a Kinetex XB $2.0 \mu \mathrm{m}$ C18 $100 \mathrm{~A}, 100 \times 2.1 \mathrm{~mm}$ (Phenomenex, Macclesfield, UK): mobile phase 90:10, 0.05M potassium dihydrogen orthophosphate adjusted to $\mathrm{pH} \mathrm{3}$; acetonitrile: flow rate $0.2 \mathrm{~mL}$ per minute; injection volume $10 \mu \mathrm{L}$; detection wavelength $298 \mathrm{~nm}$; acquisition time $5.0 \mathrm{~min}$; column temperature ambient; and autosampler temperature $5^{\circ} \mathrm{C}$.

\section{Preparation of solutions for analysis}

Phials of meropenem powder $1 \mathrm{~g}$ were used to prepare lowconcentration and high-concentration solutions (approximately $6.25 \mathrm{mg} / \mathrm{mL}$ and $25 \mathrm{mg} / \mathrm{mL}$ ) in triplicate in a variety of solutions. Solutions were placed in $30 \mathrm{~mL}$ universal containers (Fisher) protected from light and stored at $32^{\circ} \mathrm{C}$ in a fan-assisted thermostatically controlled incubator (Sanyo Medical). At each time point, $100 \mu \mathrm{L}$ of the sample was withdrawn, diluted in the same buffer to contain approximately $0.1 \mathrm{mg} / \mathrm{mL}$ and analysed by HPLC. A small aliquot (approximately $2 \mathrm{~mL}$ ) was transferred to a universal tube for $\mathrm{pH}$ determination.

The following buffers/pH values (adjusted with citric acid) were tested: $0.9 \% \mathrm{w} / \mathrm{v}$ sodium chloride (unbuffered control), $0.3 \% \mathrm{w} / \mathrm{v}$ sodium citrate buffer $\mathrm{pH} 7,0.5 \% \mathrm{w} / \mathrm{v}$ sodium citrate buffer $\mathrm{pH} 6,1 \% \mathrm{w} / \mathrm{v}$ sodium citrate buffer $\mathrm{pH} 6,5 \% \mathrm{w} / \mathrm{v}$ sodium citrate buffer $\mathrm{pH} 6$ and $5 \% \mathrm{w} / \mathrm{v}$ phosphate buffer $\mathrm{pH} 6 . \mathrm{pH}$ was determined using a glass combination electrode and Orion $420 \mathrm{~A} \mathrm{pH}$ metre calibrated using National Institute of Standards and Technology traceable standards (Thermo Fisher Scientific, Loughborough, UK).

Meropenem standards $(\mathrm{n}=2)$ containing 0.1 and $0.05 \mathrm{mg} / \mathrm{mL}$ were prepared in water and injected $(n=6)$ at the beginning of an HPLC run to demonstrate system precision, and $0.1 \mathrm{mg} / \mathrm{mL}$ employed as a bracketing standard throughout the analysis. All standard and test samples were prepared and injected in triplicate. Samples were stored at $5^{\circ} \mathrm{C}$ during HPLC analysis and were completed within 12 hours of sample preparation to avoid additional degradation.

\section{Validation of the HPLC method}

Linearity of detector (LOD) response was demonstrated over the range of $0.01-0.20 \mathrm{mg} / \mathrm{mL}$ with $\mathrm{R}^{2}$ values (correlation coefficient) of $0.9997-0.9999(\mathrm{n}=4)$. The LOD was $0.097 \mu \mathrm{g} /$ $\mathrm{mL}$ and limit of quantitation $0.295 \mu \mathrm{g} / \mathrm{mL}$. Precision and accuracy assessments were performed with triplicate injections at a concentration of $0.1 \mathrm{mg} / \mathrm{mL}$. The mean \% relative standard deviations were $0.18 \%(\mathrm{n}=12)$ and not greater than $0.4 \%(\mathrm{n}=4)$, respectively.

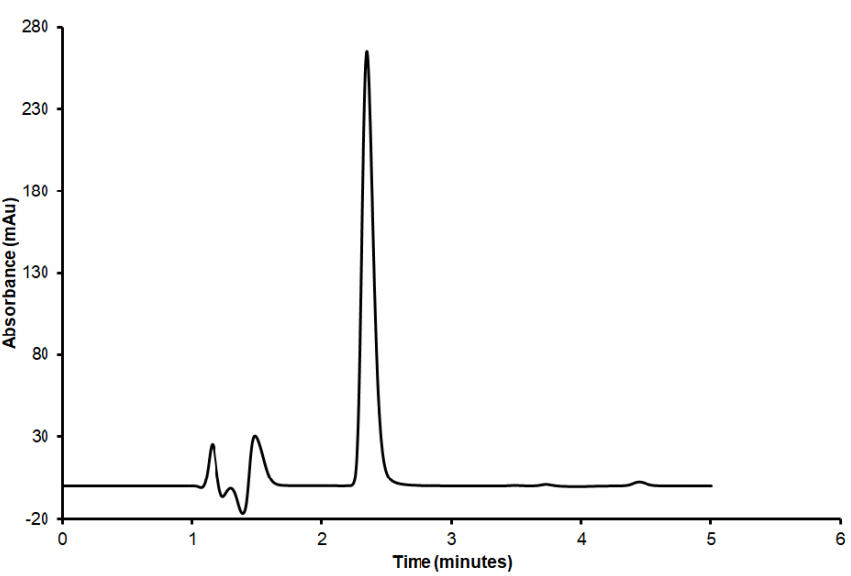

Figure 1 A typical chromatogram of meropenem (retention time $2.3 \mathrm{~min}$ ) at $1 \mathrm{mg} / \mathrm{mL}$ under forced degradation conditions of $0.1 \mathrm{M}$ hydrochloric acid after $5 \mathrm{~min}$ incubation. Detection performed at $298 \mathrm{~nm}$.

To show the method was stability-indicating, a forced degradation study was performed under the following conditions: $0.1 \mathrm{M}$ hydrochloric acid, $0.1 \mathrm{M}$ sodium hydroxide and $3 \% \mathrm{v} / \mathrm{v}$ hydrogen peroxide. Meropenem was prepared in each of the three chemically forcing solution conditions, stored at $50^{\circ} \mathrm{C}$, sampled immediately after preparation and after 30,60 and $120 \mathrm{~min}$.

The peak purity of the active meropenem peak was evaluated stored in hydrochloric acid and hydrogen peroxide by generation of a peak match using the Chromeleon V.6.8 software, where the spectra of the peak are compared with a reference spectra at three positions-front (50\%), top (100\%) and end of peak $(-50 \%)$-and scored from 1000 . The relative SD of the peak match was also calculated. All spectra had a score match $>900$ and low RSDs. The above supports the method being stability-indicating for meropenem.

\section{RESULTS}

A stability-indicating HPLC diode array method was developed to fully separate all degradation species from the active meropenem. An example of a typical chromatogram showing separation of the active meropenem peak at a retention time of $2.3 \mathrm{~min}$ from all degradant peaks is shown in figure 1 .

In solutions in $0.1 \mathrm{M}$ hydrochloric acid stored at ambient temperature, the meropenem peak area had reduced by greater than $90 \%$ after $30 \mathrm{~min}$ storage. Degradation peaks were noted to be fully separated from the meropenem peak. In $0.1 \mathrm{M}$ sodium hydroxide, it was observed that no additional degradation peaks were detectable at time 0 and degradation took place at a slower rate than occurred under acid conditions. In $3 \% \mathrm{v} / \mathrm{v}$ hydrogen peroxide, more than $90 \%$ degradation occurred after $30 \mathrm{~min}$ storage. The degradation peaks were clearly resolved under each stress condition from the meropenem peak. Acid and alkali degradation produced the same degradation product.

Peak purity for the meropenem peak with generation of a peak match under each stress condition was performed using Chromeleon V.6.8. The spectra of each peak were compared with the reference spectra at three peak positions-front (50\%), top $(100 \%)$ and tail $(-50 \%)$-and scored from 1000 . The relative SD of the peak match was reported. All spectra had a score match $>900$ and low RSDs. The above supports the method being stability-indicating for meropenem.

Meropenem degradation was assessed at different time intervals during the first 5 hours following preparation and at 


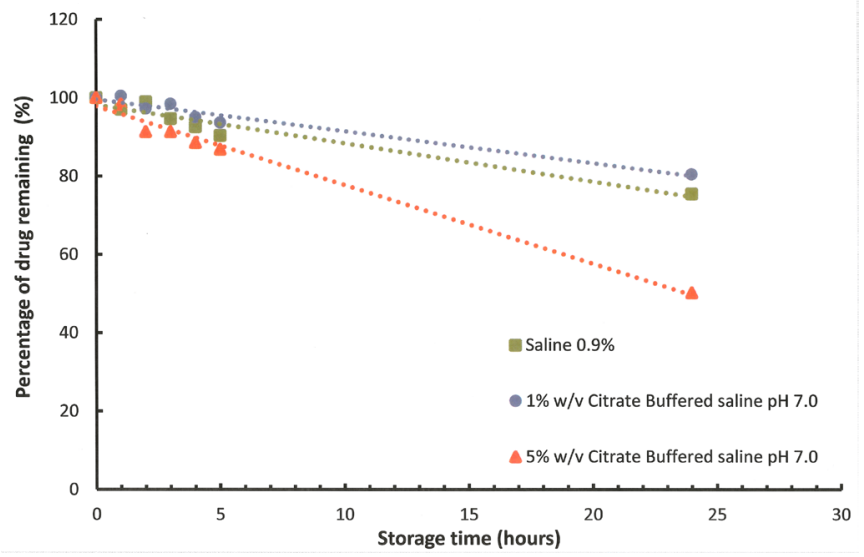

Figure 2 Degradation rates at $32^{\circ} \mathrm{C}$ of low-concentration meropenem $(6.25 \mathrm{mg} / \mathrm{mL})$ in different buffered diluents.

24-hour storage time to determine the kinetics of the degradation reaction. The results show that meropenem after reconstitution and dilution in aqueous solution is unstable, the degradation rate resulting in between approximately $20 \%$ and $56 \%$ loss after 24 hours at $32^{\circ} \mathrm{C}$ (figures 2 and 3 ).

Meropenem content and $\mathrm{pH}$ values before and after storage at $32^{\circ} \mathrm{C}$ for 24 hours in different buffered diluents are shown in table 1 . Meropenem after reconstitution and dilution in aqueous solution was unstable, with $\sim 56 \%$ degradation loss recorded for low concentrations prepared in $5 \% \mathrm{w} / \mathrm{v}$ citrate buffered saline $\mathrm{pH} 6$ after 24 hours at $32^{\circ} \mathrm{C}$. Meropenem was less stable in phosphate buffer, even when the $\mathrm{pH}$ was approximately 6.0, the optimum $\mathrm{pH}$ for stability. In solutions buffered using citrate, all the solutions showed higher $\mathrm{pH}$ values after adding meropenem. In contrast, phosphate-buffered solutions reflected the buffer $\mathrm{pH}$ more closely. The greatest losses of drug were observed at the higher meropenem concentration. Analysis of \% meropenem remaining at $\mathrm{T}=24$ hours was performed using a paired t-test with equal variance for the data using $0.9 \%$ saline unbuffered as a control. At $25 \mathrm{mg} / \mathrm{mL}$ the greatest difference (loss) in $\%$ meropenem remaining at $\mathrm{T}=24$ hours was identified in $5 \%$ phosphate-buffered $\mathrm{pH} 6.0$ using the t-test $\left(\mathrm{p}=9.15 \times 10^{-12}\right)$. The null hypothesis that there was no significant difference was therefore rejected. Meropenem at $6.25 \mathrm{mg} / \mathrm{mL}$ prepared in highstrength buffers (5\% citrate and phosphate) resulted in significant loss of meropenem compared with the saline confirmed

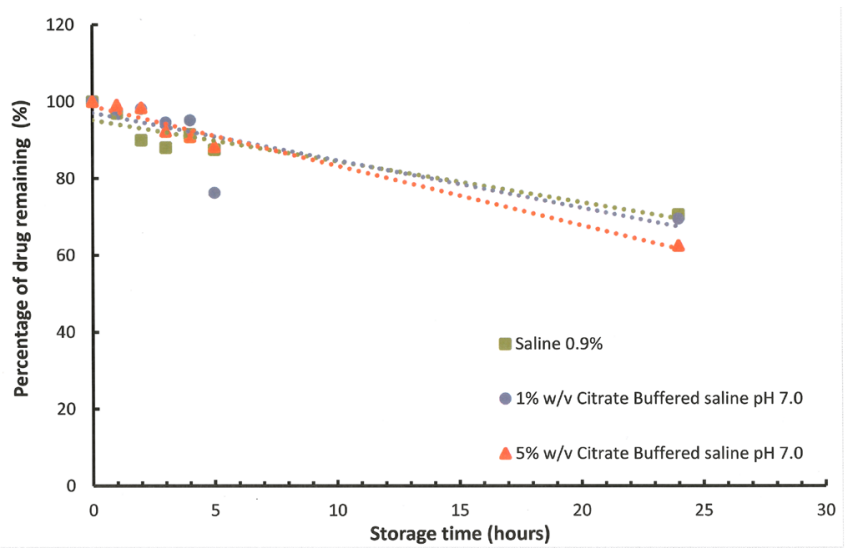

Figure 3 Degradation rates of high-concentration meropenem (25 mg/ $\mathrm{mL}$ ) at $32^{\circ} \mathrm{C}$ in different buffered diluents. with a t-test $\left(p=2.4 \times 10^{-8}, p=7.5 \times 10^{-10}\right)$ for citrate and phosphate, respectively.

\section{DISCUSSION}

Meropenem is an attractive candidate for use in OPAT services as its broad spectrum of activity includes many clinically significant multidrug-resistant pathogens, such as Pseudomonas aeruginosa and extended spectrum beta-lactamase-producing Enterobacteriaceae. ${ }^{12}$ The British Society for Antimicrobial Chemotherapy manages an OPAT-centred initiative (www.e-opat.com) that aims to support the development, quality and cost-effectiveness of OPAT services through development and promotion of OPAT service good practice recommendations, ${ }^{13}{ }^{14}$ development of a national outcomes registry and promotion of antimicrobial stewardship within OPAT. ${ }^{15}$ Fundamental to these initiatives is the availability of robust drug stability data to support the use of antimicrobial agents in OPAT services, when drugs are given as extended infusions in elastomeric devices.

The present study has been conducted in accordance with the temperature requirements of the $\mathrm{YCD}^{9}$ and was intended to assess the stability of meropenem at two clinically relevant concentrations in saline and buffered saline solutions that could be used in clinical practice.

The main degradation pathway for meropenem in aqueous solution is through the opening of the beta-lactam ring. The drug was designed to have higher chemical stability than non-1beta-substituted carbapenem drugs through decreased basicity and nucleophilicity of the basic part of the C-2 side chain. ${ }^{16}$ The degradation rate is influenced by the concentration of meropenem in the solution, with degradation rates higher at the higher concentration tested across all of the buffered and unbuffered solutions tested, which can be attributed to intermolecular aminolysis through the C-2 side chain of one meropenem molecule undergoing nucleophilic attack of the beta-lactam carbonyl of a second molecule of meropenem.

Degradation rates are also influenced by $\mathrm{pH}$ and choice of buffering agent. The concentration of meropenem has an effect on the $\mathrm{pH}$ of unbuffered, weakly buffered and strongly buffered solutions. In addition, $\mathrm{pH}$ tends to decrease after storage. Degradation may be greater in phosphate buffer compared with either unbuffered or citrate buffered solutions. Data suggest that meropenem is less stable in phosphate buffer, even when the $\mathrm{pH}$ is maintained at 6.0 , which according to published evidence is the optimum $\mathrm{pH}$ for stability. ${ }^{10}$ In the present study, when meropenem is reconstituted in citrate buffer, the most stable solutions would appear to have an approximate $\mathrm{pH}$ of 7 . However, generally it is observed that the lower the $\mathrm{pH}$ from the optimum of $\mathrm{pH} 7$ the greater the degradation rate is, irrespective of the buffering agent used. These results suggest that degradation rates are lowest around $\mathrm{pH} 7$ (without or with buffering), and is substantially greater at $\mathrm{pH} 6$, which is contrary to published evidence. $^{1011}$

It must be concluded from all these results that meropenem is too unstable to include in services requiring extended storage in infusion ambulatory devices. In addition, the rates of loss are too great to assign a 24-hour infusion period, even when prepared immediately before commencing administration. If the YCD 95\% minimum content limit is applied, the infusion period must be reduced to less than 6 hours, especially at the high concentration studied $(25 \mathrm{mg} / \mathrm{mL})$. Storage at $2^{\circ} \mathrm{C}-8^{\circ} \mathrm{C}$ prior to administration would add to the degradation losses of meropenem. ${ }^{10} \mathrm{Calcu}-$ lations for the meropenem degradation rate of minus $1 \%$ per 24 hours at $4^{\circ} \mathrm{C}$ are consistent with the published rate constant 
Table 1 Meropenem content and $\mathrm{pH}$ before and after storage at $32^{\circ} \mathrm{C}$ for 24 hours in different buffered diluents

\begin{tabular}{|c|c|c|c|c|c|c|}
\hline \multirow[b]{2}{*}{ Meropenem concentration } & \multirow[b]{2}{*}{ Diluent } & \multicolumn{2}{|c|}{ Mean concentration $(\mathrm{mg} / \mathrm{mL}) \pm(95 \% \mathrm{Cl})$} & \multirow{2}{*}{$\begin{array}{l}\text { Meropenem remaining at } \mathrm{T}=24 \text { hours, } \\
\% \pm(95 \% \mathrm{Cl})\end{array}$} & \multicolumn{2}{|l|}{$\mathrm{pH}$} \\
\hline & & $\mathrm{T}=0$ & $\mathrm{~T}=24$ hours at $32^{\circ} \mathrm{C}$ & & $\mathrm{T}=0$ & $\mathrm{~T}=24$ hours at $32^{\circ} \mathrm{C}$ \\
\hline \multirow[t]{3}{*}{$25 \mathrm{mg} / \mathrm{mL}$} & $0.9 \%$ sodium chloride (unbuffered) & $26.71 \pm(0.02)$ & $17.58 \pm(0.10)$ & $65.838383 \pm(0.35)$ & 7.80 & 7.56 \\
\hline & $1 \%$ citrate buffer at $\mathrm{pH} 6.0$ & $22.08 \pm(0.09)$ & $15.90 \pm(0.04)$ & $72.00 \pm(0.11)$ & 6.85 & 6.83 \\
\hline & $5 \%$ phosphate buffer at $\mathrm{pH} 6.0$ & $24.62 \pm(0.08)$ & $11.54 \pm(0.02)$ & $46.86 \pm(0.09)$ & 6.18 & 5.97 \\
\hline \multirow[t]{6}{*}{$6.25 \mathrm{mg} / \mathrm{mL}$} & $0.9 \%$ sodium chloride (unbuffered) & $6.27 \pm(0.02)$ & $5.18 \pm(0.02)$ & $82.59 \pm(0.23)$ & 7.68 & 7.51 \\
\hline & $0.3 \%$ citrate buffer at $\mathrm{pH} 7.0$ & $6.25 \pm(0.01)$ & $5.13 \pm(0.01)$ & $82.05 \pm(0.02)$ & 7.87 & 7.56 \\
\hline & $0.5 \%$ citrate buffer at $\mathrm{pH} 6.0$ & $6.33 \pm(0.02)$ & $5.24 \pm(0.01)$ & $82.84 \pm(0.29)$ & 6.93 & 7.01 \\
\hline & $1 \%$ citrate buffer at $\mathrm{pH} 6.0$ & $6.19 \pm(0.02)$ & $5.30 \pm(0.02)$ & $85.60 \pm(0.08)$ & 7.05 & 7.02 \\
\hline & $5 \%$ citrate buffer at $\mathrm{pH} 6.0$ & $5.94 \pm(0.03)$ & $2.64 \pm(0.08)$ & $44.51 \pm(1.29)$ & 6.15 & 6.00 \\
\hline & $5 \%$ phosphate buffer at $\mathrm{pH} 6.0$ & $6.04 \pm(0.05)$ & $2.50 \pm(0.04)$ & $41.41 \pm(0.55)$ & 5.90 & 5.76 \\
\hline
\end{tabular}

by Takasu et al. ${ }^{10}$ Attempts to improve meropenem stability by the use of buffering have failed to make sufficient improvement to degradation rates to support 24-hour CI of meropenem. For safe and effective use of meropenem in the OPAT setting, reconstitution and intermittent administration by either healthcare workers or trained patients/carers are recommended. Changing the meropenem ambulatory device every 6 hours, the likely requirement to keep degradation below the 5\% allowed in the YCD, is likely to be unrealistic for many OPAT services.

Franceschi et al studied meropenem at $5 \mathrm{mg} / \mathrm{mL}$ and reported stability for CI for up to 8 hours providing the temperature was kept between $25^{\circ} \mathrm{C}$ to $35^{\circ} \mathrm{C}^{7}$. Under these conditions $>90 \%$ of meropenem remained at the end of administration satisfying the European Pharmacopoeia requirements. Manning et al reported clinical outcomes in a cohort of 50 patients with a variety of infections receiving CI of meropenem in elastomeric devices, the majority of which were not cooled, with 8 patients (16\%) being cured, 33 patients $(66 \%)$ demonstrating improvement while 9 patients $(18 \%)$ failed treatment over a six year period. ${ }^{12}$ In their stability studies of $1 \%$ and $2 \%$ meropenem solutions in cooled and uncooled devices, losses ranged from 10 to 27\%. Modelling

\section{What this paper adds}

\section{What is already known on this subject}

- Meropenem is a broad-spectrum antibiotic used to treat serious infections in hospitals, particularly those caused by multidrug-resistant Gram-negative bacteria.

- The pharmacokinetics/pharmacodynamics characteristics of meropenem suggest that a continuous 24-hour infusion would be advantageous and would suit many outpatient parenteral antimicrobial therapy (OPAT) services.

- Meropenem is known to be unstable in aqueous solution, which limits its potential for OPAT.

\section{What this study adds}

- It was not possible to stabilise meropenem using a variety of buffered solutions such that $>95 \%$ of the meropenem remained at the end of the administration period.

- The latest National Health Service Pharmaceutical Quality Assurance Committee Yellow Cover Document (YCD) requires that $>95 \%$ of the API should remain at the end of the administration period.

- Maximum infusion time should be limited to no more than 6 hours to limit the loss of meropenem to $<5 \%$ and comply with the $Y C D$, rendering meropenem unsuitable for most OPAT services where a once daily infusion of antibiotic is preferred. work showed that the uncooled $2 \%$ infuser would deliver $87.2 \%$ of the maximum deliverable dose. Our conclusion is that meropenem is insufficiently stable to allow for continuous infusion in elastomeric devices for time periods exceeding 6 hours, based on YCD and British Pharmacopoeia requirements. Data from Manning et al suggest that a lower threshold of stability may be acceptable in clinical practice, but we would urge caution until there is a better understanding of the degradation products of meropenem, and any likely clinical impact. There is scope for a re-examination of pharmacopoeial standards for stability of meropenem and an international consensus on what is safe and acceptable in clinical practice.

Acknowledgements The authors would like to thank all members of the BSAC Drug Stability Working Party who contributed to the study and production of the manuscript. The BSAC Drug Stability Working Party comprise CJ (Chair), Mark Gilchrist, TH, Mark Santillo and Andrew Seaton, and representatives from the stability testing laboratory, MCA and A-SW.

Contributors A-SW and CJ planned the study. DS and AW performed the study and collected the data. A-SW, MCA, DS, AW and CJ analysed the data and wrote the manuscript. CJ, TH and other members of the BSAC Drug Stability Working Party critically reviewed the manuscript.

Funding This study was commissioned and funded by the British Society for Antimicrobial Chemotherapy (BSAC) as part of their Drug Stability Testing Programme in the UK to support outpatient parenteral antimicrobial therapy (OPAT) services

Competing interests None declared.

Patient consent for publication Not required.

Provenance and peer review Not commissioned; externally peer reviewed.

Data sharing statement The outputs of the research are published open access in line with the BSAC policy and will be freely disseminated, including being made available through the BSAC Drug Stability Testing Programme website: www.bsacdsp.com.

Open access This is an open access article distributed in accordance with the Creative Commons Attribution Non Commercial (CC BY-NC 4.0) license, which permits others to distribute, remix, adapt, build upon this work non-commercially, and license their derivative works on different terms, provided the original work is properly cited, an indication of whether changes were made, and the use is noncommercial. See: http://creativecommons.org/licenses/by-nc/4.0/.

\section{REFERENCES}

1 Baldwin CM, Lyseng-Williamson KA, Keam SJ. Meropenem: a review of its use in the treatment of serious bacterial infections. Drugs 2008;68:803-38.

2 Chapman AL. Outpatient parenteral antimicrobial therapy. BMJ 2013;346:f1585.

3 Allwood MC, Stonkute D, Wallace A, et al. Assessment of the stability of citratebuffered flucloxacillin for injection when stored in two commercially available ambulatory elastomeric devices: INfusor LV (Baxter) and Accufuser (Woo Young Medical): a study compliant with the NHS Yellow Cover Document (YCD) requirements. Eur J Hosp Pharm 2020;27:90-4.

4 Craig WA. Pharmacokinetic/pharmacodynamic parameters: rationale for antibacterial dosing of mice and men. Clin Infect Dis 1998;26:1-10. quiz 1-2. 
5 Chytra I, Stepan M, Benes J, et al. Clinical and microbiological efficacy of continuous versus intermittent application of meropenem in critically ill patients: a randomized open-label controlled trial. Crit Care 2012;16:R113.

6 Lorente L, Lorenzo L, Martín MM, et al. Meropenem by continuous versus intermittent infusion in ventilator-associated pneumonia due to gram-negative bacilli. Ann Pharmacother 2006:40:219-23.

7 Franceschi L, Cojutti P, Baraldo M, et al. Stability of generic meropenem solutions for administration by continuous infusion at normal and elevated temperatures. Ther Drug Monit 2014;36:674-6.

8 Mollá-Cantavella S, Ferriols-Lisart R, Torrecilla-Junyent T, et al. Intravenous meropenem stability in physiological saline at room temperature. Eur J Hosp Pharm Sci Pract 2014;21:202-7.

9 PharmaceuticalNHS CAQ. Standard Protocol for Deriving and Assessment of Stability, Part 1: Aseptic Preparations (Small Molecules), Edition 4, April 2017 (Yellow Cover, 2017.

10 Takasu Y, Yoshida M, Tange M, et al. Prediction of the stability of meropenem in intravenous mixtures. Chem Pharm Bull 2015;63:248-54.
11 Takeuchi Y, Sunagawa M, Isobe Y, et al. Stability of a 1 beta-methylcarbapenem antibiotic, meropenem (SM-7338) in aqueous solution. Chem Pharm Bull 1995;43:689-92

12 Manning L, Wright C, Ingram PR, et al. Continuous infusions of meropenem in ambulatory care: clinical efficacy, safety and stability. PLoS One 2014;9:e102023.

13 Chapman AL, Seaton RA, Cooper MA, et al. Good practice recommendations for outpatient parenteral antimicrobial therapy (OPAT) in adults in the UK: a consensus statement. J Antimicrob Chemother 2012;67:1053-62.

14 Patel S, Abrahamson E, Goldring S, et al. Good practice recommendations for paediatric outpatient parenteral antibiotic therapy (p-OPAT) in the UK: a consensus statement. J Antimicrob Chemother 2015;70:360-73.

15 Gilchrist M, Seaton RA. Outpatient parenteral antimicrobial therapy and antimicrobial stewardship: challenges and checklists. J Antimicrob Chemother 2015;70:965-70

16 Papp-Wallace KM, Endimiani A, Taracila MA, et al. Carbapenems: past, present, and future. Antimicrob Agents Chemother 2011;55:4943-60. 